\title{
Synthesizing crystalline carbon nitrides by using two different bio-molecular materials
}

\author{
Cheng-Tzu Kuo ${ }^{\mathrm{a}, *}$, Jin-Yu Wu ${ }^{\mathrm{a}}$, Tien-Rong Lu ${ }^{\mathrm{b}}$ \\ ${ }^{a}$ Department of Materials Science and Engineering, National Chiao Tung University, Hsinchu 300, Taiwan \\ ${ }^{\mathrm{b}}$ Ritek Display Technology Corporation, Hsinchu Industrial Park, Hsinchu 303, Taiwan
}

\begin{abstract}
It is important to examine the deposition mechanism of crystalline carbon nitrides and to investigate the linkage between bio-molecular and superhard materials. Two different $\mathrm{CN}$ compound bio-molecular targets with the sixfold ring structure similar to that in the hypothetical $\beta-\mathrm{C}_{3} \mathrm{~N}_{4}$ were proposed to be used for synthesizing carbon nitride films on different substrates by reactive ion beam sputtering. Effect of the substrate material and the correlation between the bonding characters of the different target materials and the deposited films were examined. The deposited films exhibit no significant differences in the atomic N/C ratio and film properties at the condition of $1000 \mathrm{eV}$ Ar-ion beam, no matter which one of the two target materials and which one of the seven substrate materials are. The XPS and AES analyses reveal that the atomic N/C ratio of the films can go up to 0.50, which is much higher than most of the reported values (0.2-0.35). The FTIR, XPS and Raman spectra clearly indicate the co-existence of chemical bondings of $\mathrm{C}-\mathrm{N}$ single bond and $\mathrm{C}=\mathrm{N}$ double bond; and no detectable $\mathrm{C} \equiv \mathrm{N}$ triple bonding is observed, which forms a favor basis for further processing of the films to improve the film quality. The XRD, electron diffraction, TEM and AFM analyses indicate that the deposited films may consist of the nano-sized $\beta-\mathrm{C}_{3} \mathrm{~N}_{4}$ crystallites embedded in matrix of graphite form of $\mathrm{C}_{3} \mathrm{~N}_{4}$ structure, and the volume concentrations of the crystalline phases are high enough to be detected by XRD. The implication of the results is that one highly probable way to explore the deposition mechanisms of crystalline carbon nitrides is to manipulate chemical bonding information using different target materials. (C) 2001 Elsevier Science B.V. All rights reserved.
\end{abstract}

Keywords: Nitrides; Ion beam-assisted deposition; Electron diffraction; AES; AFM

\section{Introduction}

The theoretical calculation of carbon nitride $\left(\mathrm{C}_{3} \mathrm{~N}_{4}\right)$ was first reported by Liu and Cohen [1] in 1989, and was concluded to be a new superhard compound with a bulk modulus comparable to that of diamond. It is also predicted that the carbon nitride can possess superior oxidation resistance, chemical inertness, wear resistance and thermal conductivity; and can be a wide band gap semiconductor material [2]. Over the last few years, many efforts to prepare the carbon nitride films have focused on various techniques, such as laser ablation [3], DC magnetron sputtering [4], RF sputtering [5], ion deposition [6], ion implantation [7], plasma arc deposition [8], chemical vapor deposition [9], shock wave high pressure synthesis [10], organic pyrolysis [11] and UV-assisted chemical synthesis [12]. However, the theoretically predicted crystalline $\mathrm{C}_{3} \mathrm{~N}_{4}$ has not been successfully synthesized by these techniques so far. Most experimental results show no or poor X-ray diffraction (XRD) evidence of the crystalline carbon nitride phases, suggesting the volume

\footnotetext{
* Corresponding author. Tel.: +886-3-5731-949; fax: +886-3-5724-727. E-mail address: ctkuo@cc.nctu.edu.tw (C.-T. Kuo).
}

of the crystalline phases is less than 5\% of the total volume of the deposited film. Therefore, their evidence of crystallinity of the films is generally the selected area electron diffraction patterns from nano- to micron-sized crystallites [3]. In addition to possessing a low atomic N/C ratio $(0.2-0.35)$, their films are essentially small percentages of crystallites embedded in an amorphous matrix $[3,8,12]$. The crystalline films with bigger crystal sizes (several tens of microns) were reported by Chen et al. [9]; however, it is essentially a $\mathrm{Si}-\mathrm{C}-\mathrm{N}$ ternary system. A high atomic N/C ratio of 1.39 was reported by Diani et al. [13]; however, their results show formation of amorphous films which consist of some $\mathrm{C} \equiv \mathrm{N}$ triple bonding and are readily decomposed at about $600{ }^{\circ} \mathrm{C}$, indicating a poor thermal stability. Further, the presence of $\mathrm{C} \equiv \mathrm{N}$ bonding precluded an extended carbon nitride solid, since the triply bonded nitrogen breaks the continuity of the network.

From the reported literatures, it is found that most of the research efforts have been focused on developing different activation techniques. The possibility of using different carbon and nitrogen sources has been rarely emphasized. In the past, most of the raw materials of carbon and nitrogen sources for synthesis of carbon nitrides were limited to methane, graphite, nitrogen gas and ammonia $[7,14,15]$. It 
is believed that the raw materials with a high atomic N/C ratio and/or possessing similar atomic bonding structure as that in hypothetical $\beta-\mathrm{C}_{3} \mathrm{~N}_{4}$ will be a good starting precursor for carbon nitride synthesis due to the possibility of providing abundant $\mathrm{CN}$ species. Furthermore, perhaps the linkage between bio-molecular materials and superhard materials will be an interesting topic in physics, and may give an excellent key to open the truth on nucleation and growth mechanisms for formation of crystalline carbon nitrides. Therefore, in this work, two different bio-molecular materials were selected as target to synthesize the crystalline carbon nitrides by an ion beam sputtering system.

\section{Experimental}

By using an ion beam sputtering system, two different bio-molecular compounds of adenine (hereafter, short for 6-aminopurine, $\mathrm{C}_{5} \mathrm{~N}_{5} \mathrm{H}_{5}$ ) and azaadenine (hereafter, short for 8-aza-6-aminopurine, $\mathrm{C}_{4} \mathrm{~N}_{6} \mathrm{H}_{5}$ ) were selected as the target materials. As shown in Fig. 1, adenine and azaadenine contain $\mathrm{C}-\mathrm{N}$ single bonds and $\mathrm{C}=\mathrm{N}$ double bonds, and exhibit a sixfold ring structure quite similar to that in the hypothetical $\beta-\mathrm{C}_{3} \mathrm{~N}_{4}$. The white powders of the bio-materials were first baked at $105^{\circ} \mathrm{C}$ for $24 \mathrm{~h}$ in a flowing nitrogen atmosphere to remove moisture, and were then compacted to form a 1 in. disk target at a pressure of $1250 \mathrm{~kg} \mathrm{~cm}^{-2}$. The substrates for film deposition include (1 111$) \mathrm{Si}$ wafer, (1 00 ) B-doped Si wafer, AISI-304 stainless steel, Cu, Ag, $\mathrm{Co}$ and $\mathrm{Ni}$. The deposition conditions are: target-substrate distance, $20 \mathrm{~cm}$; pressure before deposition, $10^{-6}$ Torr; pressure during deposition, $2-4 \times 10^{-4}$ Torr; Ar flow rate, $1 \mathrm{sccm}$; deposition time, $30-120 \mathrm{~min}$; substrate temperature, $50-60^{\circ} \mathrm{C}$; maximum target temperature, $90^{\circ} \mathrm{C}$; energy of<smiles>Nc1ncnc2[nH]nnc12</smiles>

Azaadenine<smiles>Nc1ncnc2[nH]cnc12</smiles>

Adenine
Fig. 1. Molecular structure of adenine and azaadenine compounds.

Ar-ion beam, $350-1000 \mathrm{eV}$. To focus on the effect of target material, except the $\mathrm{N}$ source from the bio-molecular targets and the substrate heating from ion bombing, no other additional activated nitrogen sources and the substrate heating were provided. The deposited films were characterized by XPS, Auger electron spectrum (AES), FTIR, Raman spectroscopy, XRD, AFM and TEM.

\section{Results and discussion}

\subsection{Effect of substrate and target material on deposition}

One advantage of this system is that an uniform and dense crystalline carbon nitride films over a 4 in. wafer could be obtained at the substrate temperatures close to ambient temperature $\left(50-60^{\circ} \mathrm{C}\right)$, indicating a process of low activation energy. At the condition of $1000 \mathrm{eV}$ argon-ion beam energy, the highest target temperature $90^{\circ} \mathrm{C}$ is still much lower than the melting temperatures of about $360^{\circ} \mathrm{C}$ for both target materials. Therefore, the deposition process is essentially a sputtering process with insignificant contribution from vaporization process. The results show no significant differences in the atomic N/C ratio and the film properties for seven different substrates. This may be due to a low deposition temperature.

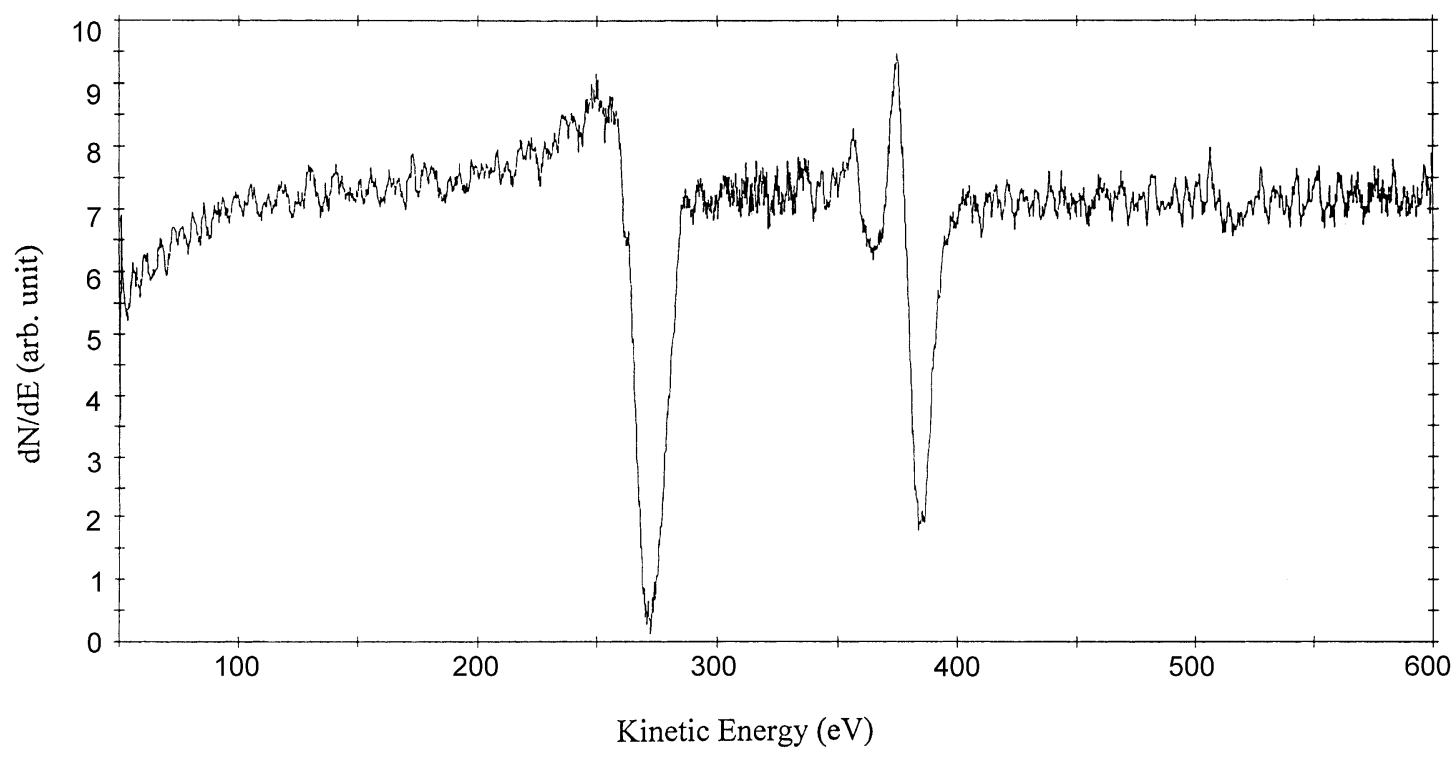

Fig. 2. Auger spectrum of the films. 
To examine the effect of target material, adenine and azaadenine targets were examined in this work. It is noted that at the condition of $1000 \mathrm{eV}$ argon-ion beam energy, no differences in films properties were found, whatever adenine or azaadenine target was adopted. This may imply that the predominant nucleation and growth mechanism for these two different target materials is quite similar. Compared with the raw materials (i.e., methane, graphite, nitrogen gas and ammonia) used in the literature [7,14,15], the reported $\mathrm{N} / \mathrm{C}$ atomic ratios are low (0.2-0.35). It may also indicate that the manipulation of chemical bonding information by changing different target materials can be an effective way of exploring the growth mechanism of crystalline carbon nitrides. This is under further investigation.

\subsection{Atomic N/C ratio of the films}

Fig. 2 shows a typical AES for the films deposited on AISI-304 stainless steel at $1000 \mathrm{eV}$ argon-ion beam bombardment. There are no peaks for oxygen or other impurities except two significant peaks at 272 and $380 \mathrm{eV}$ for $\mathrm{C}$ and $\mathrm{N}$, respectively, indicating a high content in $\mathrm{C}$ and $\mathrm{N}$. The deposited films were also examined by scanning Auger mapping, revealing that the $\mathrm{N}$ and $\mathrm{C}$ distributions on the film surface are quite uniform. From the results of XPS and Auger analyses, the film composition is close to $\mathrm{C}_{2} \mathrm{~N}$, i.e., the average atomic $\mathrm{N} / \mathrm{C}$ ratio of 0.50 , which is in good agreement with the result of 0.47 from ESCA analysis. The same N/C ratio was reported by Lieber and coworkers [3], but their films were deposited under condition of providing additional nitrogen atom source by laser ablation. This implies that $\mathrm{C}_{2} \mathrm{~N}$ may be a relatively stable metastable phase in $\mathrm{C}-\mathrm{N}$ phase diagram, as two quite different processes can obtain it. The N/C value of the present films is higher than most of the reported values $(0.2-0.35)$ in the literature $[7,14,15]$. It is also noted that the N/C ratio of the films is much less than that of the two precursors (bio-molecular target materials). This signifies that the process can be a reactive ion beam sputtering process through decomposing the target material by ion beam. Therefore, different sputtering conditions may give different degrees of dissociation of target material and result in different film properties. Moreover, it may suggest that both adenine and azaadenine targets are beneficial to the formation of carbon nitride films by providing $\mathrm{CN}$ species with higher N/C ratios during argon-ion beam bombardment.

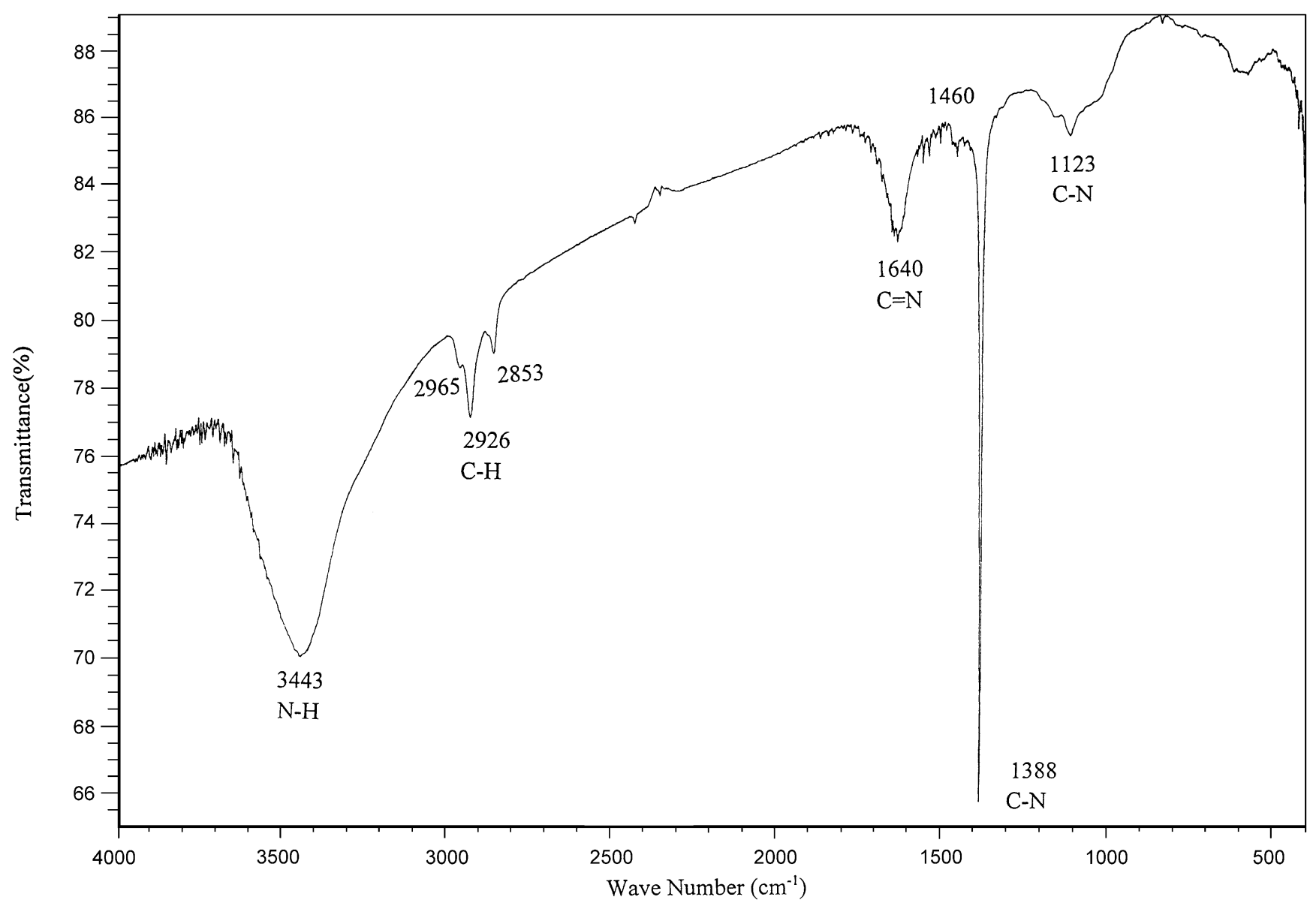

Fig. 3. FTIR spectrum of the films. 


\subsection{Bonding states of $C-N$}

To examine the bonding states, the deposited films were scratched out from the substrate, ground into powders, mixed with $\mathrm{KBr}$ powders and compacted to form a disk for FTIR examination. The typical FTIR spectrum is depicted in Fig. 3. The peaks at 1123,1388 and $1640 \mathrm{~cm}^{-1}$ are corresponding to $\mathrm{C}-\mathrm{N}$ single and $\mathrm{C}=\mathrm{N}$ double stretching bonds, respectively [16]. The peaks at 3443 and $2853-2965 \mathrm{~cm}^{-1}$ are attributed to the $\mathrm{N}-\mathrm{H}$ and $\mathrm{C}-\mathrm{H}$ bonds, respectively. No significant peaks around $2190 \mathrm{~cm}^{-1}$ corresponding to $\mathrm{C} \equiv \mathrm{N}$ triple stretching bond can be found in Fig. 3. This indicates that the films possess a good bonding character for further processing of the films to improve the film quality, because of no existence of $\mathrm{C} \equiv \mathrm{N}$ triple bond in the films.

The Raman spectrum of the films is shown in Fig. 4. Two weak peaks at 1325.5 and $1551.2 \mathrm{~cm}^{-1}$ correspond to higher binding energies D $\left(1360 \mathrm{~cm}^{-1}\right)$ and $\mathrm{G}\left(1575 \mathrm{~cm}^{-1}\right)$ band absorption peaks of amorphous carbon. A slight shift in Raman peaks to a lower frequency side is in agreement with the results reported by Bousetta et al. [17] due to a higher concentration of nitrogen in the present films.

The typical XPS spectra are shown in Fig. 5. A slight shift in XPS peaks is in agreement with the results of some investigators [18-20], and is attributed to the following reasons. The incorporation of nitrogen in the a-C:H matrix can induce a charge transfer from less electronegative $\mathrm{C}$ (2.5) atoms to the more electronegative $\mathrm{N}$ (3.0) atoms. Therefore, as more homopolar $\mathrm{C}-\mathrm{C}$ bonds are replaced by heteropolar $\mathrm{C}-\mathrm{N}$ bonds, a decrease in the electron density on the $\mathrm{C}$ atoms will result in a shift of all $\mathrm{C}$ core levels towards higher binding energies [21]. For carbon atom, the $285.5 \mathrm{eV}$ signal is corresponding to energy for $\mathrm{sp}^{2}$ hybrid orbits of $\mathrm{C}_{1 \mathrm{~s}}$ and $\mathrm{N}$, and the $287.5 \mathrm{eV}$ signal for $\mathrm{sp}^{3}$ hybrid orbits of $\mathrm{C}_{1 \mathrm{~s}}$ and $\mathrm{N}$. This is also in agreement with the results reported by Marton et al. [22]. For nitrogen atom, the $399.4 \mathrm{eV}$ signal is corresponding to energy for $\mathrm{sp}^{3}$ hybrid orbits of $\mathrm{N}_{1 \mathrm{~s}}$ and $\mathrm{C}$, and $401.1 \mathrm{eV}$ signal for $\mathrm{sp}^{2}$ hybrid orbits for $\mathrm{N}_{1 \mathrm{~s}}$ and $\mathrm{C}$. All these bonding characterization results once again indicate the existence of chemical bonding with no significant physical bonding between $\mathrm{C}$ and $\mathrm{N}$.

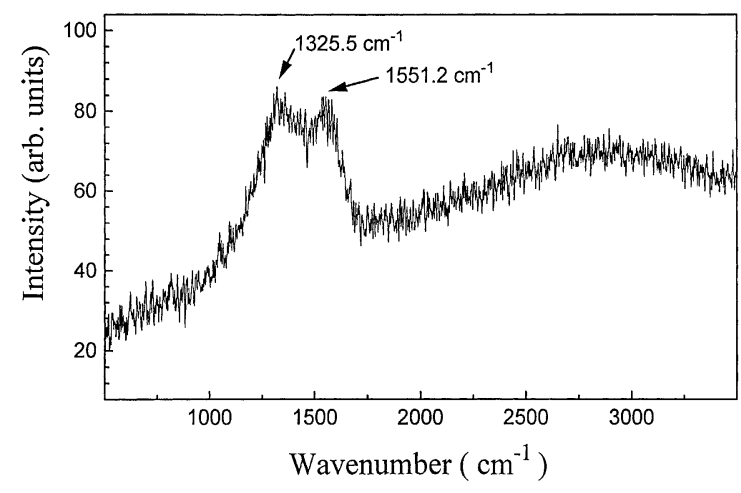

Fig. 4. Raman spectrum of the films.
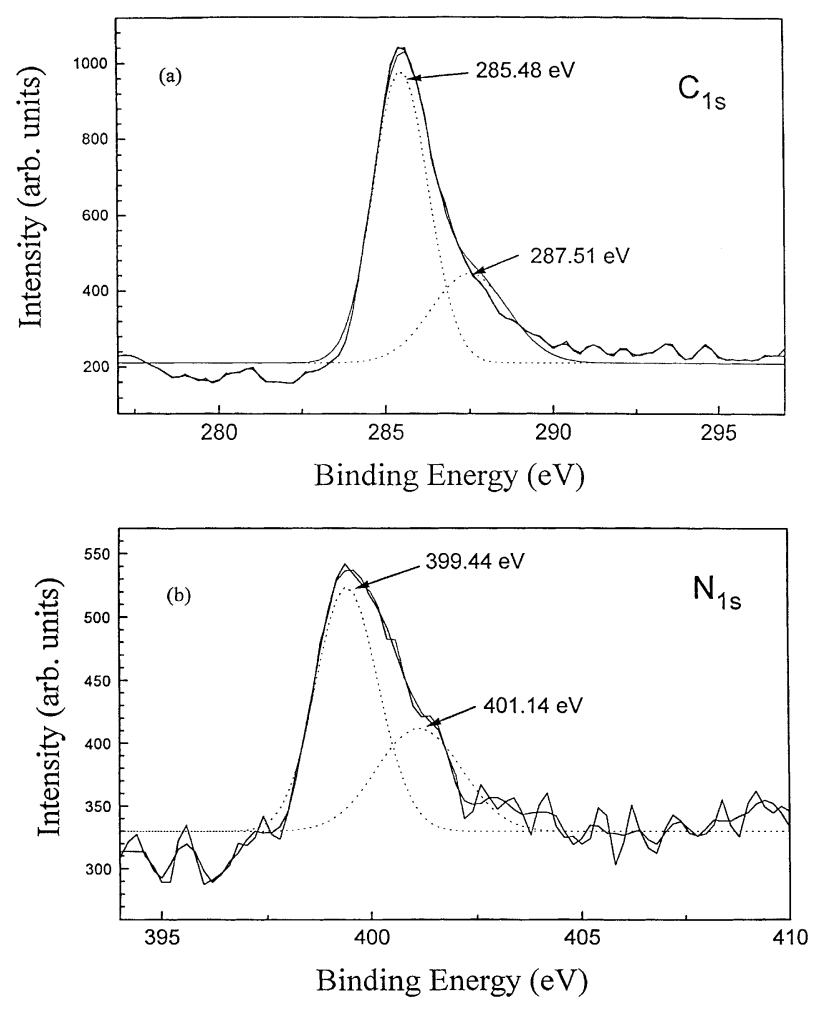

Fig. 5. XPS spectra of the films for: (a) $\mathrm{C}_{1 \mathrm{~s}}$; (b) $\mathrm{N}_{1 \mathrm{~s}}$.

\subsection{Crystal structure and morphology of the films}

On crystal structure examination, the typical XRD pattern at low incident angle is shown in Fig. 6, together with XRD patterns of graphite and two target materials. The interplane spacing $(d)$ for the strongest diffraction peak at $2 \theta=27.20^{\circ}$ is $0.3276 \mathrm{~nm}$, which is smaller than the strongest peak with $0.3505 \mathrm{~nm}$ spacing of (0 0 3) plane of graphite. This may imply that the crystal structure of the present films is close to graphite form of $\mathrm{C}_{3} \mathrm{~N}_{4}$ structure. This is in agreement with the fact that van der Waals carbon bonding from instantaneous dipole interactions between $\left(\begin{array}{lll}0 & 0 & 3\end{array}\right)$ planes of graphite is weaker than van der Waals $\mathrm{CN}$ bonding from permanent dipole interactions of graphite form of $\mathrm{C}_{3} \mathrm{~N}_{4}$ structure. The spacing of the strongest peak of the present films is also close to $0.3200 \mathrm{~nm}$ spacing of (1 1 0) plane of the theoretical $\beta-\mathrm{C}_{3} \mathrm{~N}_{4}$ structure [23]. This suggests that the crystallinity and the volume concentration of the crystalline phases in the films are high enough to be detected by XRD. It is also noted that the XRD peak of carbon nitride is broadening due to very small crystal sizes in the films. This is also supported in Fig. 7 for a typical AFM micrograph of the films, where the original surface morphology of the stainless steel substrate is still visible after covering a layer of the film. The peak broadening is also in good agreement with TEM bright field and dark field images in Fig. 8, showing dense and uniformly distributed nano-sized crystallites embedded in, perhaps, graphite matrix. 


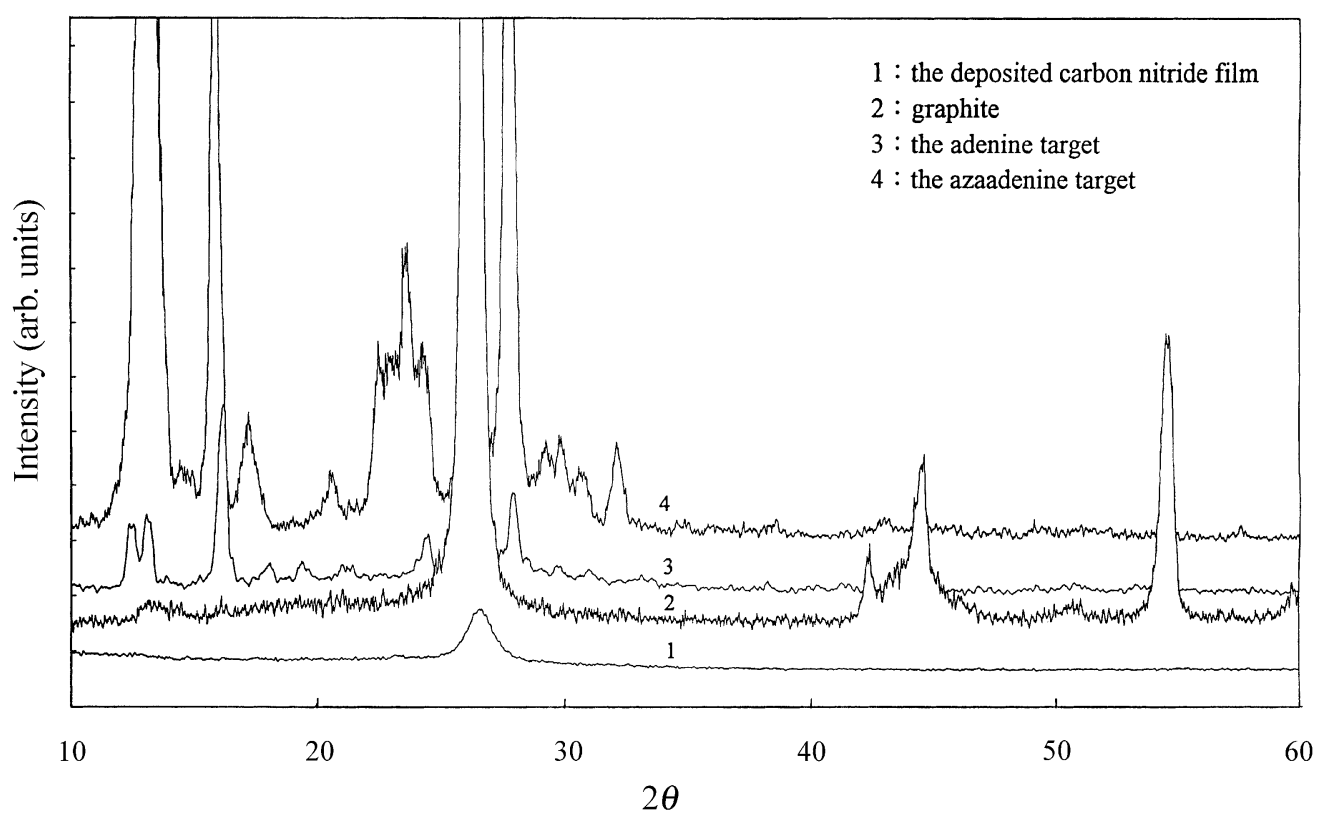

Fig. 6. XRD profile of the films on stainless steel substrate at low incident angle.

Similar to XRD results, the interplane spacings calculated from electron diffraction of the present films are also in reasonable agreement with that of graphite form of $\mathrm{C}_{3} \mathrm{~N}_{4}$ structure. The hardness of the films is low, which is a typical property for graphite-form structure. To examine the crystal structure of the crystallites in the films, Fig. 9 depicts a typical selected area electron diffraction pattern of a nano-sized crystal. Although the present films may contain only a small percentage of the $\beta-\mathrm{C}_{3} \mathrm{~N}_{4}$ phase according to the result of N/C ratio, the $d$-spacings for each diffraction ring are $0.5570,0.3189,0.2606,0.2073,0.1809,0.1601$ and $0.1280 \mathrm{~nm}$, respectively, which are close to the correspond-

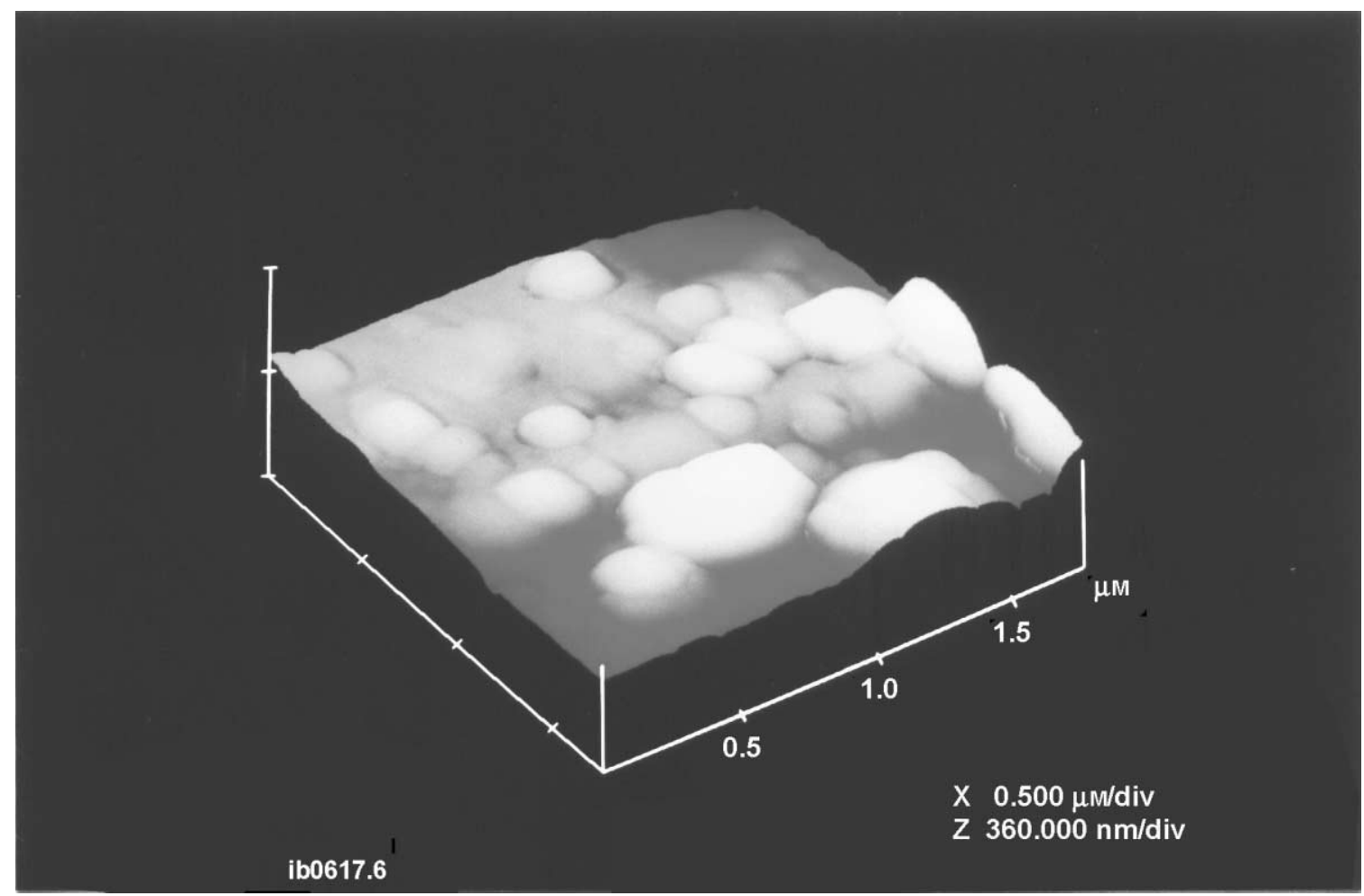

Fig. 7. AFM image of the films on stainless steel substrate 


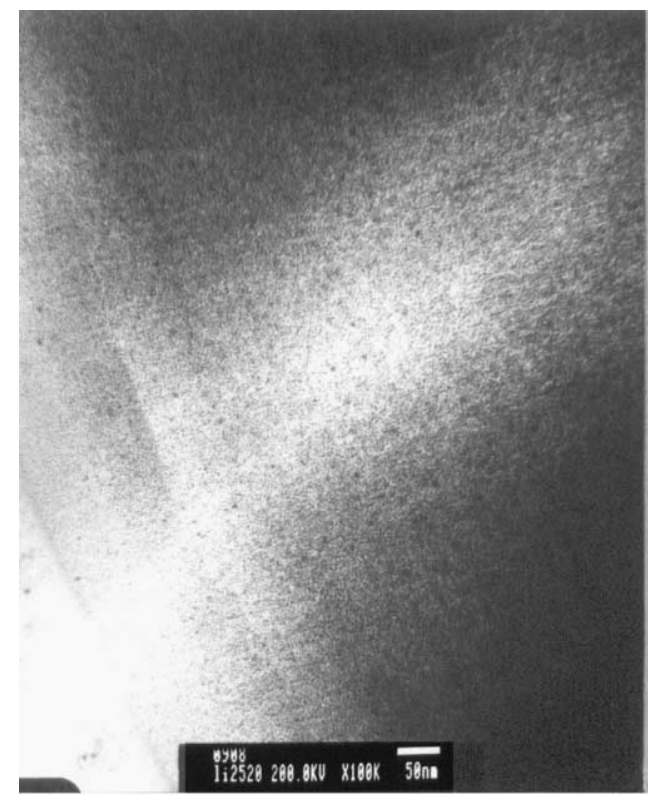

(a)

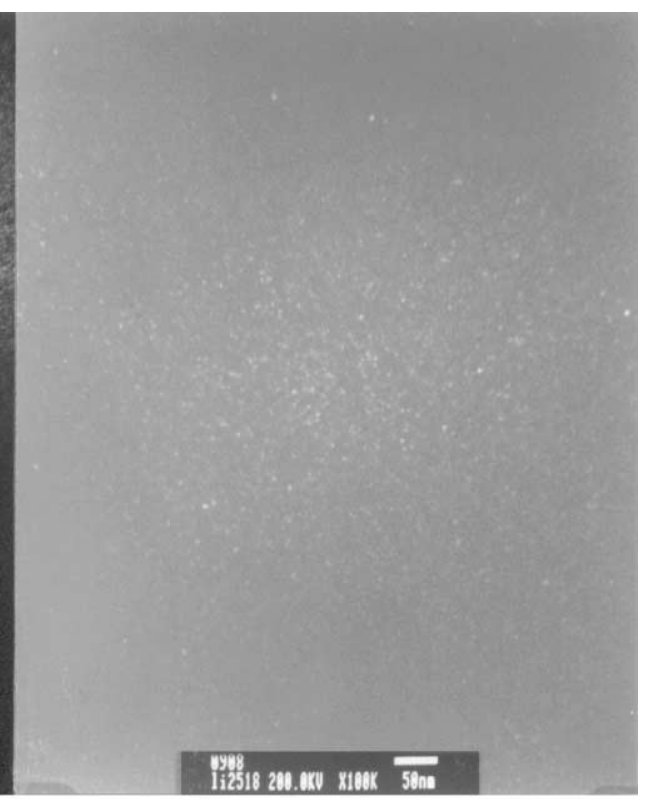

(b)

Fig. 8. TEM images of the films: (a) bright field; (b) dark field.

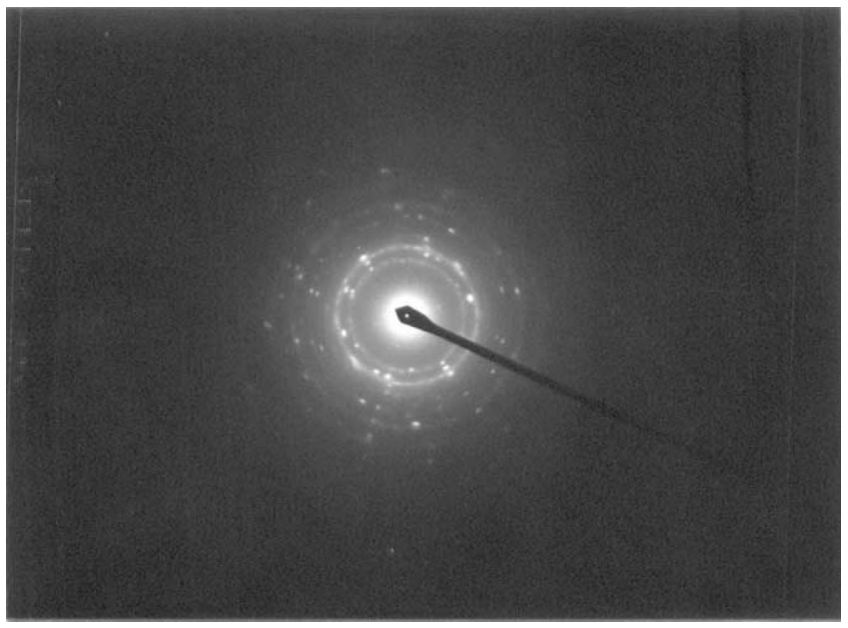

Fig. 9. Electron diffraction pattern of the films.

ing spacings of the theoretical $\beta-\mathrm{C}_{3} \mathrm{~N}_{4}$ structure: $0.5500 \mathrm{~nm}$ for (100), $0.3170 \mathrm{~nm}$ for $(110), 0.2750 \mathrm{~nm}$ for $(200)$, $0.2080 \mathrm{~nm}$ for $(210), 0.1830 \mathrm{~nm}$ for $(300), 0.1592 \mathrm{~nm}$ for (211) and $0.1260 \mathrm{~nm}$ for (320), respectively [23]. The (1 110$)$ diffraction is also present in XRD pattern in Fig. 6.

\section{Conclusions}

From the experimental results, it is concluded that the two bio-molecular targets, i.e., adenine and azaadenine, were successfully demonstrated to be able to deposit the crystalline carbon nitride films. Both XPS and AES analyses indicate high $\mathrm{C}$ and $\mathrm{N}$ contents in the films with the atomic
$\mathrm{N} / \mathrm{C}$ ratio of about 0.5 . The FTIR, Raman and XPS analyses confirm the chemical bonding between $\mathrm{C}$ and $\mathrm{N}$ atoms. The $\mathrm{XRD}$, electron diffraction, TEM and AFM analyses indicate that the deposited films may consist of the nano-sized $\beta-\mathrm{C}_{3} \mathrm{~N}_{4}$ crystallites embedded in matrix of graphite form of $\mathrm{C}_{3} \mathrm{~N}_{4}$ structure, and the volume concentrations of the crystalline phases are high enough to be detected by XRD. The differences in film properties deposited by using different raw materials in the literatures and in this work, it may suggest that the manipulation of chemical bonding information by changing different target materials and deposition conditions can be an effective key to explore the formation mechanisms of crystalline carbon nitrides.

\section{Acknowledgements}

This work was supported by the Ministry of Education (Grant No.: 89-E-FA06-1-4) and National Science Council of Taiwan (Grant No.: NSC89-2216-E009-041).

\section{References}

[1] A.Y. Liu, M.L. Cohen, Science 245 (1989) 841.

[2] C.M. Sung, M. Sung, Mater. Chem. Phys. 43 (1996) 1.

[3] C. Niu, Y.Z. Lu, C.M. Lieber, Science 261 (1993) 334.

[4] D. Li, S. Lopez, Y.M. Chung, M.S. Wong, W.D. Sproul, J. Vac. Sci. Technol. A 13 (3) (1995) 1063.

[5] K.M. Yu, M.L. Cohen, E.E. Haller, W.L. Hansen, A.Y. Liu, I.C. Wu, Phys. Rev. B 49 (1994) 5034.

[6] K.J. Boyd, D. Marton, S.S. Todorov, A.H. Al-Bayati, J. Kulik, R.A. Zuhr, J.W. Rabalais, J. Vac. Sci. Technol. A 13 (1995) 2110.

[7] A. Hoffman, I. Gouzman, R. Brener, Appl. Phys. Lett. 64 (1994) 845. 
[8] T.Y. Yen, C.P. Chou, Appl. Phys. Lett. 67 (1995) 6.

[9] L.C. Chen, D.M. Bhusari, C.Y. Yang, K.H. Chen, T.J. Chuang, M.C. Lin, C.K. Chen, Y.F. Haung, Thin Solid Films 303 (1997) 66.

[10] D.C. Nesting, J.V. Badding, Chem. Mater. 8 (1996) 1535.

[11] M. Todd, J. Kouvetakis, T.L. Groy, D. Chandrasekhar, D.J. Smith, P.W. Deal, Chem. Mater. 7 (1995) 1422.

[12] T.-R. Lu, C.-T. Kuo, T.M. Chen, Thin Solid Films 308 (1997) 126.

[13] M. Diani, A. Mansour, L. Kubler, J.L. Bischoff, D. Bolmont, Diam. Relat. Mater. 5 (1996) 514.

[14] M. Tabbal, P. Merel, S. Moisa, M. Chaker, A. Ricard, M. Moisan, Appl. Phys. Lett. 69 (1996) 1698.

[15] D.F. Franceschini, F.L. Freire Jr., S.R.P. Silva, Appl. Phys. Lett. 68 (1996) 2654.
[16] X.A. Zhao, C.W. Ong, Y.C. Tsang, Y.W. Wong, P.W. Chan, C.L. Choy, Appl. Phys. Lett. 66 (1995) 2652.

[17] A. Bousetta, M. Lu, A. Bensaoula, A. Schultz, Appl. Phys. Lett. 65 (1994) 696.

[18] H. Sjostrom, L. Hultman, J.-E. Sundgren, S.V. Hainsworth, T.F. Page, G.S.A.M. Theunissen, J. Vac. Sci. Technol. A 14 (1) (1996) 56.

[19] T. Okada, S. Yamada, Y. Takeuchi, T. Wada, J. Appl. Phys. 78 (12) (1995) 7416.

[20] H. Sjostrom, W. Lanford, B. Hjorvarson, K. Xing, J.E. Sundgren, J. Mater. Res. 12 (4) (1996) 981.

[21] A. Mansour, D. Ugolini, Phys. Rev. B 47 (1993) 10201.

[22] D. Marton, K.J. Boyd, A.H. Al-Bayati, S.S. Todorov, J.W. Rabalais, Phys. Rev. Lett. 73 (1994) 118.

[23] E.E. Haller, M.L. Cohen, W.L. Hansen, US Patent 5110679 (1992). 